results when applied universally, and that even in the same person there were significant discrepancies. ${ }^{6}$ Our findings confirm and amplify these earlier observations and those of other workers. ${ }^{13-16}$ In particular, Entiknap and Wright described similar disparities in a study of two volunteers. ${ }^{16}$ The relevant blood:breath ratios averaged $2475: 1$, which was not significantly different from the ratio of 2470 obtained from the 24 volunteers studied by Payne et al ${ }^{6}$ Moreover, in both subjects significant changes in the ratio occurred for short periods during the experiment. Entiknap and Wright suggested that on balance a figure of $1: 2370$ for the breath:blood ratio "seems a reasonable guess." But "a reasonable guess" should not be used to obtain a conviction in a court of law.

In a later study similar values were reported by Jones, who obtained blood:breath ratios that averaged 2367 (range 21202950 ) in 15 volunteers. " In each of his volunteers the ratios changed during the course of the experiment by as much as $24 \%$. The pattern of these blood:breath ratios corresponds to the pattern that we found, although our ratio for five subjects at 2271 was slightly lower and our range of 1123 to 3100 considerably wider.

More recently Jones et al: have attempted to reassess the value of breath analysis. According to their calculations the results derived from 78 comparisons of capillary blood values with breath values showed a line of best fit at a ratio of $2300: 1$, although no hard data were presented to allow an independent check. Clearly therefore the blood:breath ratio not only varies from person to person but also widely in the same person with time.

A possible explanation for these variations was suggested by Payne et $a l,{ }^{6}$ who pointed out that equilibrium between pulmonary blood and alveolar air can be achieved only when inspired air is perfectly distributed within the lungs relative to the pulmonary blood flow, that even in healthy people some degree of ventilation-perfusion inequality exists, and that such inequality is greater in the presence of established lung disease. Furthermore, even if equilibrium were reached between pulmonary blood and alveolar air it is unlikely that the mucus secretions of the bronchial tree would also reach equilibrium at the same speed. Thus some exchange of alcohol vapour might be expected to take place between breath and mucus during passage along the bronchial tree, particularly during the early stages of absorption.

Accordingly, as has been argued, ${ }^{17}$ the blood:breath ratio should be regarded as nothing more than a statistical convenience suitable for defining the limits of a particular universe. Its use to derive individual blood alcohol levels from breath alcohol levels has little scientific justification, and, more particularly, its use in this way for law enforcement can only be deplored. We reiterate our view that breath analysis is not an acceptable method for accurately determining blood alcohol concentrations.

\section{References}

1 Road Traffic Act 1972. London, HMSO, 1972.

2 Powell, T, Proceedings of the Royal Society of Medicine, 1966, 59, 904.

3 Alobaidi, T A A, PhD Thesis, University of London, 1974

4 Alobaidi, T A A, and Hill, D W, fournal of Physics E, 1975, 8, 30.

${ }^{5}$ Hill, D W, and Newell, H A, fournal of Scientific Instruments, 1965, 42, 783.

6 Payne, J P, Hill, D W, and King, N W, British Medical fournal, 1966, $1,196$.

7 Curry, A S, Walker, G W, and Simpson, G S, Analyst, 1966, 91, 742.

${ }^{8}$ British Medical Association, The Drinking Driver, London, BMA, 1965.

9 Penton, J R, and Forrester, M R, Proceedings of the 5th International Conference on Alcohol and Traffic Safety, p 79. Freiburg, Germany, H F Schutz Verlag, 1969.

${ }^{10}$ Jones, A W, PhD Thesis, University of Wales Institute of Science and Technology, 1974.

11 Dubowski, K M, Clinical Chemistry, 1974, 20, 294

12 Jones, A W, Wright, B M, and Jones, T P, Praceedings of the 6th International Conference on Alcohol, Drugs, and Traffic Safety, p 509. Toronto. The Addiction Research Foundation, 1975.

${ }^{13}$ Bayly, R C, McCallum, N E W, and Preston, W K L, Proceedings of the Royal Australian Chemical Institute, 1960, 27, 157.

${ }^{14}$ Harger, R N, Proceedings of the 3rd International Conference on Alcohol and Road Safety, p 212. London, BMA, 1963.

15 Begg, T B, Hill, I D, and Nickolls, L C, British Medical fournal, 1964, 1, 9.

${ }^{16}$ Entiknap, J P, and Wright, B M, Proceedings of the 4th International Conference on Alcohol and Traffic Safety, p 161. Bloomington, Indiana, Indiana University, 1966.

17 Payne, J P, Proceedings of the Royal Society of Medicine, 1975, 68, 375.

\title{
Coagulation and fibrinolysis in intact hydatidiform molar pregnancy
}

\author{
F H M TSAKOK, S KOH, S S RATNAM
}

British Medical fournal, 1976, 2, 1481-1484

\section{Summary}

Tests of coagulation, fibrinolysis, and platelet function were performed in 17 patients with intact molar pregnancies. Women with intact molar pregnancies had higher fibrinogen, factor VIII, and fibrinogen degradation products, concentrations and lower prothrombin, factor $\mathbf{X}$, plasminogen, and plasminogen activator concentra-

\footnotetext{
Department of Obstetrics and Gynaecology, University of Singapore, Kandang Kerbau Hospital, Singapore 8

F H M TSAKOK, MRCOG, senior lecturer and consultant

$S \mathrm{KOH}$, senior laboratory technician

S S RATNAM, FRCOG, MD, professor and head of department
}

tions than controls with normal pregnancies. They also had reduced platelet counts and thromboelastographic values, which indicated hypocoagulability. These results suggest that intravascular coagulation occurs in intact hydatidiform molar pregnancies.

\section{Introduction}

Normal pregnancy is accompanied by changes in the coagulation as well as the fibrinolytic system. These changes occur in parallel with the period of gestation, ${ }^{12}$ being minimal in the first trimester and changing progressively thereafter.

Certain abnormal pregnancy states, such as eclampsia, ${ }^{3}$ pre-eclampsia, ${ }^{45}$ intrauterine death, ${ }^{6}$ amniotic fluid embolism, ${ }^{89}$ abruptio placentae, ${ }^{10}$ and septic abortion, are also accompanied by coagulation and fibrinolytic abnormalities.

Coagulation disorders have been suspected in hydatidiform molar pregnancies when there has been a previous serious 

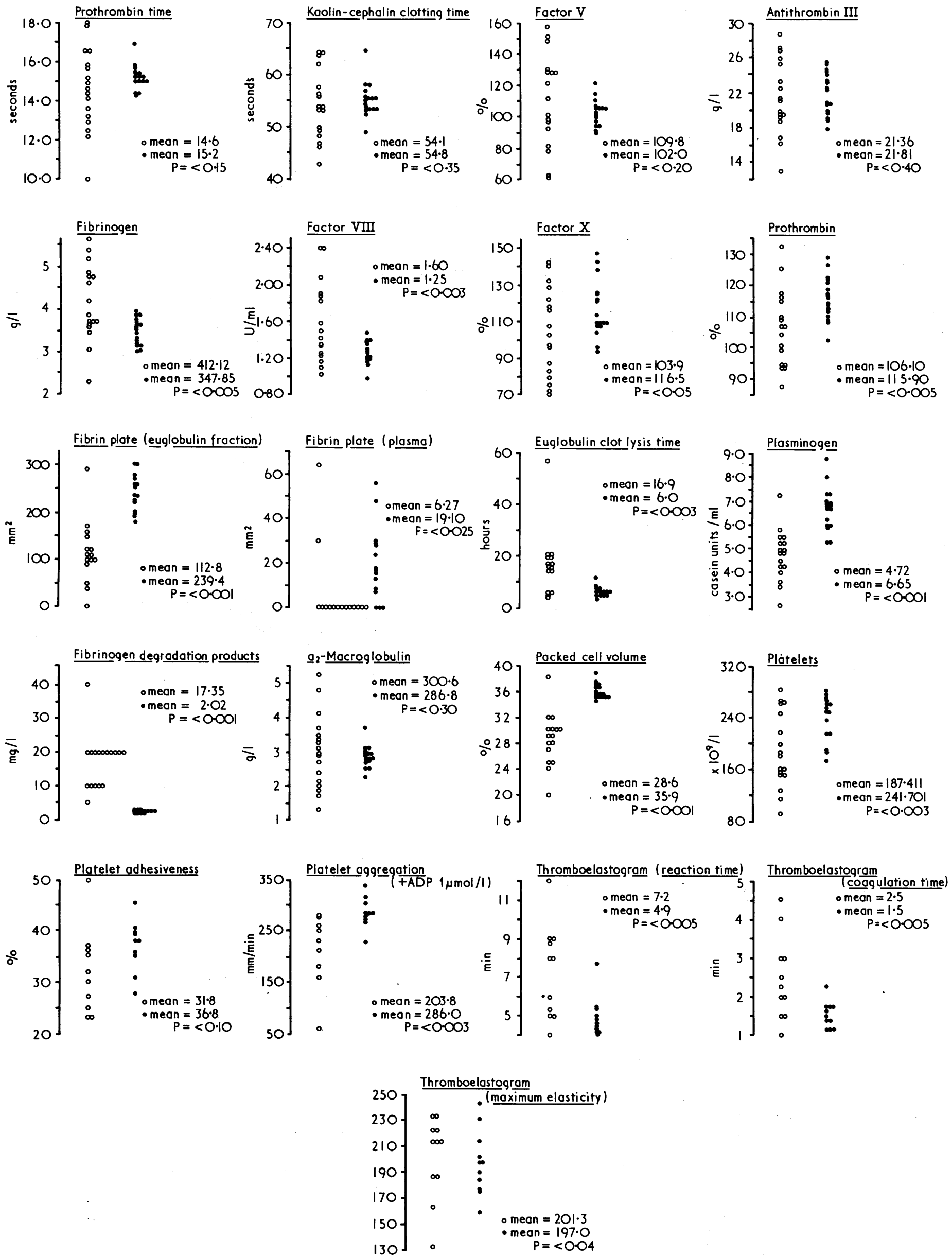

Results of coagulation, fibrinolytic, platelet, and thromboelastographic studies. $O=$ Molar pregnancies. $Q=$ Mean of values from four normal pregnancies 
haemorrhage. A few investigators have detected hypofibrinogenaemia ${ }^{11}$ and a clotting defect in isolated cases. In one fatal case of mole a prominent finding was the widespread deposition of fibrin. ${ }^{12}$ Since hydatidiform moles are often accompanied by pre-eclampsia, changes in the coagulation mechanisms can be expected. It is also known that in hydatidiform molar pregnancy, dissemination of trophoblastic tissue is fairly common. Trophoblastic tissue has thromboplastic activity and therefore may affect the coagulation system.

Information on this issue should also be useful in elucidating the cause of abnormal and excessive bleeding so common in this condition, but so far there has been no detailed study on the coagulation and fibrinolytic system in hydatidiform molar pregnancies. We present here a preliminary report of coagulation, fibrinolysis and platelet function in 17 intact hydatidiform molar pregnancies.

\section{Patients and methods}

Seventeen patients who had hydatidiform molar pregnancies at 12 to 16 weeks of gestation were studied. Molar pregnancy was usually diagnosed on the basis of a high level of human chorionic gonadotrophin and by ultrasound B-scan or amniogram. We deduced that the mole was still intact from the fact that no products of conception or vesicles had been passed out per vaginam and that the uterus was larger than normal for the period of gestation.

Four normal pregnancies were used as controls for each molar pregnancy. These patients were matched for age, ethnic group, and gestation.

Venous blood was collected with plastic syringes and plasma samples were obtained by mixing nine volumes of whole blood with one volume of HEPES citrate centrifuged at $4 \mathrm{C}$. Serum added to epsilonaminocaproic acid and thrombin was used to assay fibrinogen degradation products. Plain serum from clotted blood was used for the electrophoretic tests. Blood added to edetic acid was sedimented and the plasma used for platelet count. Most of the coagulation fibrinolytic tests were performed within an hour of collecting the blood, which was kept at $4 \mathrm{C}$.

The following coagulation indices were measured: one-stage prothrombin time, ${ }^{13}$ kaolin-cephalin clotting time, ${ }^{13}$ fibrinogen, ${ }^{14}$ prothrombin (factor II), ${ }^{15}$ factor $V,{ }^{16}$ factor VIII, ${ }^{17}$ factor $X,{ }^{18}$ and serum antithrombin III. ${ }^{19}$

To test fibrinolysis we measured plasminogen levels, ${ }^{20} \quad \alpha_{2}$-macroglobulin, ${ }^{21}$ and serum fibrinogen degradation products. ${ }^{22}$ The ethanol gelation test was performed. ${ }^{23}$ Fibrinolytic activity of plasma and resuspended euglobulin precipitate was measured on fibrin plates according to the method of Astrup and Mullertz $\mathrm{Z}^{23}$ as modified by Nilsson and Olow. ${ }^{24}$ Euglobulin lysis time was also measured.

Platelet count was performed using the Coulter counter. We measured platelet adhesiveness, by the method of Hellem ${ }^{26}$ as modified by Hirsh et $a l,,^{27}$ and platelet adenosine diphosphate aggregation. ${ }^{28}$ Thromboelastographic studies were performed on fresh plasma samples as developed by Hartet. ${ }^{29}$ These measure all phases of blood coagulation by continuous visual and photokymographic observation. These assays were used as a measure of the overall coagulability of the blood.

Values in women with molar pregnancies and their matched controls were compared with a matched $t$ test.

\section{Results}

The results of all the tests are shown in the figure.

Screening tests-The mean prothrombin time and kaolin-cephalin clotting times were similar in both groups.

Coagulation tests-Values for each patient with an intact hydatidiform mole were compared with the mean value of her four controls. Mean factor V and antithrombin III levels were similar in both groups. Plasma fibrinogen levels and factor VIII levels were significantly higher in patients with moles and factor $\mathrm{X}$ and prothrombin levels were significantly lower.

Fibrinolytic tests-The results of the fibrinolytic tests are shown in the figure. All apart from $\alpha_{2}$-macroglobulin levels, indicated a considerable difference between molar and normal pregnancies. The packed cell volume was much lower in those with hydatidiform moles.

Platelet tests-The patients' platelet counts were slightly lower than the controls' counts. Tests of adhesiveness showed no significant difference among the groups, although the aggregation with adenosine diphosphate was significantly impaired in those with molar pregnancies.

Thromboelastographic studies showed the reaction time and the coagulation time to be significantly longer in patients than in controls. The maximum elasticity was similar in both groups.

\section{Discussion}

Our findings show that there are differences from normal in coagulation, fibrinolysis, and platelet function in hydatidiform molar pregnancies. Hypofibrinogenaemia, reported by Beyth, ${ }^{29}$ was not found in this series of 17 intact hydatidiform molar pregnancies. In fact there was a slight increase in the fibrinogen levels in patients with moles compared with values in their controls ( $\mathbf{P}=<0.005)$. There was no significant difference in most of the coagulation factors except in factors II, VIII, and X. Factor VIII was slightly higher in molar pregnancies while factors $\mathrm{X}$ and II were slightly lower.

The most striking differences were found in the results of the fibrinolytic tests. Plasminogen was significantly lower in those with molar pregnancies than in controls $(P=<0.001)$, but fibrinogen degradation products were significantly increased $(\mathbf{P}<0.001)$. The ethanol gelation test gave a negative result for all patients.

The spontaneous fibrinolytic activity of plasma and resuspended euglobulin precipitate on fibrin plates was lower in the molar pregnancies than in the control pregnancies. This decrease was especially significant in the euglobulin precipitate. Together with the significantly longer time taken for euglobulin lysis in molar pregnancies, all these tests reflect reduced levels of circulating plasminogen activator.

The concentration of certain coagulation factors such as fibrinogen and factor VIII seem to be higher in women with moles than at the same gestation in normal pregnancy. Prothrombin and factor $\mathrm{X}$ concentrations are reduced, however, which might be the result of increased consumption due to intravascular coagulation. The platelet count was also significantly reduced, but the adhesiveness and aggregation were not significantly changed. The thromboelastographic patterns showed a decreased reaction and coagulation time, indicating hypocoagulability. The results of this investigation suggest that there is intravascular coagulation even in the intact hydatidiform molar pregnancy. There is evidence of increased fibrinolysis although levels of circulating plasminogen activators were reduced.

The coagulopathy seems to be a localised intravascular coagulation with secondary fibrinolysis. Although it is now well recognised that there is some intravascular coagulation in women with pre-eclampsia in the third trimester, ${ }^{30}$ this condition has not been confirmed in those with hydatidiform moles. Hypertension does not seem to be a requirement for intravascular coagulation to occur in molar pregnancies, since only four patients were hypertensive, one requiring hypotensive treatment.

Possibly the degree of intravascular coagulation may vary with the presence of hypertension and may also be associated with the amount of bleeding per vaginam before the mole is aborted. So does the mode of evacuation of the hydatidiform mole play any part in causing disseminated intravascular coagulation and during abortion does intravascular coagulation become disseminated?

We thank Miss Chua Siok Eng, Mr Raymond Yuen, and Miss Ho Lai Meng for their expert laboratory help. This work is supported by the Royal College of Obstetricians and Gynaecologists, the principle author having been awarded the Edgar Research Fellowship, which has enabled her to carry out this work.

\section{References}

${ }^{1}$ Bonnar, J, McNicol, G P, and Douglas, A S, British Medical fournal, 1969, 3, 387. 
2 Astedt, B, Acta Obstetrica et Gynecologica Scandinavica, 1972, 51, suppl No 18

${ }^{3}$ Henderson, A H, Paysley, D J, and Thomas, D P, British Medical fournal, $1970,3,545$.

${ }^{4}$ Bonnar, J, McNicol, G P, and Douglas, A S, British Medical fournal, 1971, 2, 12.

5 Howie, P W, Prentice, C R M, and McNicol, G P, fournal of Obstetrics and Gynaecology of the British Commonwealth, 1971, 78, 992.

6 Brakman, P, and King, A W, American fournal of Obstetrics and Gynecology, 1965, 92, 221

${ }^{7}$ Hardisty, R M, and Ingram, G I C, Bleeding Disorders, p 108. Oxford, Blackwell, 1965.

${ }^{8}$ Hardaway, R M, and McKay, D G, Annals of Surgery, 1959, 149, 462.

${ }^{\circ}$ Beller, F K, Douglas, G W, and Epstein, M D, American fournal of Obstetrics and Gynecology, 1963, 87, 48.

10 Hardaway, R M, Syndromes of Disseminated Intravascular Coagulation. Illinois, Charles C Thomas, 1966.

11 Beyth, Y, Fournal of Reproductive Medicine, 1973, 11, 223.

12 McKay, D G, et al, American fournal of Obstetrics and Gynecology, 1953, 66, 507.

13 Biggs, R, (editor), Human Blood Coagulation Haemostasis and Thrombosis, p 609. Oxford, Blackwell, 1972 .
14 Ratnoff, O D, and Menzie, C, in Blood Coagulation Haemorrhage and Thrombosis, ed L M Tocantins and L A Kazal, p 224. New York, Grune and Stratton, 1964

15 Denson, K W E, Borrett, R, and Biggs, R, British fournal of Haematology, 1971, 21, 2.

16 Shanberge, J N, Matsouka, T, and Fakui, A, American fournal of Clinical Pathology, 1967, 47, 533.

17 Biggs, R, British fournal of Haematology, 1955, 1, 20.

18 Biggs, R, British fournal of Haematology, 1970, 19, 283.

19 Hedner, U, Thrombosis Research, 1973, 3, 631.

20 Alkjaersig, N, Fletcher, A P, and Sherry, S, fournal of Clinical Investigation, $1959,38,1086$.

${ }^{21}$ Ganrot, P O, Clinica Ghimica Acta, 1966, 14, 493.

22 Merskey, C, Kleiner, G J, and Johnson, A J, Blood, 1966, 28, 1.

23 Godal, H C, Abilgaard, U, and Kieruif, P, Ginekologia Polska, 1971, 41, 971.

${ }^{24}$ Astrup, T, and Mulletz, S, Archives of Biochemistry, 1952, 40, 346.

${ }^{25}$ Nilsson, I M, and Olow, B, Acta Chirurgica Scandinavica, 1962, 123, 247.

${ }^{26}$ Hellem, A J, Scandinavian fournal of Clinical and Laboratory Investigation, 1960, 12, Suppl No 51 .

${ }^{27}$ Hirsh, J, et al, Australasian Annals of Medicine, 1966, 15, 122

${ }^{28}$ Born, G V R, and Cross, M J, Fournal of Physiology, 1963, 168, 178.

${ }^{29}$ Hartet, H, Klinische Wochenschrift, 1948, 26, 37

\section{SHORT REPORTS}

\section{Paroxysmal nocturnal haemoglobinuria-like defect in red cells in chronic lymphatic leukaemia}

A characteristic of red cells in paroxysmal nocturnal haemoglobinuria (PNH) is their increased sensitivity to lysis by complement, especially when tested in acidified serum. The clinical syndrome of PNH has been well described in association with hypoplastic anaemias, ${ }^{1}$ and occasional cases associated with acute myeloid leukaemia and myelosclerosis have been recorded. ${ }^{2}$ We report the development of PNH in a case of chronic lymphatic leukaemia.

\section{Case report}

A 76-year-old woman was first seen in April 1972 with dyspnoea, ankle swelling, and left lower chest pain. Examination showed anaemia; marked bilateral cervical, axillary, and inguinal lymphadenopathy; and hepatosplenomegaly. Haemoglobin was $11.1 \mathrm{~g} / \mathrm{dl}$; white cell count $270 \times 10^{\%} / 1$ $\left(270000 / \mathrm{mm}^{3}\right)$, mainly small lymphocytes; and platelet count $120 \times 10^{9} / 1$ $\left(120000 / \mathrm{mm}^{3}\right)$. Chest $x$-ray picture was normal. Chronic lymphatic leukaemia was diagnosed, and for the next 32 months she received shor intermittent courses of chlorambucil.

During the next 10 months of treatment, although chlorambucil kept the white cell count at $10-20 \times 10^{9} / 1\left(10000-20000 / \mathrm{mm}^{3}\right)$, the lymphadenopathy and splenomegaly increased despite vincristine and cyclophosphamide, and frequent transfusions were needed to maintain the haemoglobin at $9-10 \mathrm{~g} / \mathrm{dl}$.

In January 1976 the patient reported passing dark brown urine in the night after a transfusion. This occurred several times over the next few weeks, no always related to transfusion and not always nocturnal. She never had a clinical transfusion reaction. A specimen of the brown urine contained oxyhaemoglobin and methaemoglobin without microscopic haematuria. He serum consistently contained methaemalbumin but never haptoglobin. Haemosiderin was always present in her urine. She had a reticulocytosis of

Results of red-cell lysis tests

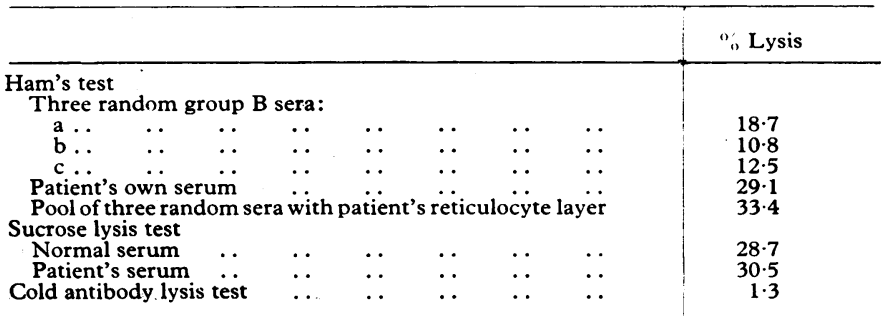

$10 \%$ with a plasma bilirubin of $44 \mu \mathrm{mol} / 1(2.6 \mathrm{mg} / 100 \mathrm{ml})$. Serum lactate dehydrogenase was $2600 \mathrm{IU} / 1$.

Serum proteins showed a normal electrophoretic pattern. Immunoglobulins were: IgG $11.6 \mathrm{~g} / \mathrm{l}, \mathrm{IgA} 0.49 \mathrm{~g} / \mathrm{l}$, and $\mathrm{IgM} 0.76 \mathrm{~g} / \mathrm{l}$. The normocellular marrow showed a diffuse infiltration with mature lymphocytes and no evidence of dyserythropoiesis. Leucocyte alkaline phosphatase score was 4 (normal 36-100). The continued presence of transfused cells precluded studies of red-cell survival. Paroxysmal cold haemoglobinuria was excluded by direct and indirect Donath-Landsteiner antibody tests. The cold agglutinin titre at $4 \mathrm{C}$ was normal at $1 / 8^{3}$ The patient was group $\mathrm{B}$ rhesus (D) positive with no irregular antibodies. Result of a direct Coombs test with a broad-spectrum reagent was negative. Red-cell acetylcholine esterase activity was $4 \cdot 1 \div 10^{3} \mathrm{U} / 1$ of red cells (normal 8-13 $\times 10^{3} \mathrm{U} / \mathrm{l}$ ). Results of redcell lysis tests are given in the table.

\section{Comment}

Hill et $a l^{4}$ described a PNH-like abnormality in a patient with a lymphoproliferative disorder. Their diagnosis was made on laboratory evidence alone, and the patient showed no features of chronic intravascular haemolysis. Our patient fulfilled the usual criteria for the diagnosis of PNH. The positive sucrose lysis test result and lysis of her cells in her own serum in Ham's test excluded hereditary erythroblastic multinuclearity with a positive acidified serum test result, and this was confirmed by the absence of abnormal erythroblasts in the marrow. We cannot explain the negative cold antibody lysis test result but consider that this did not exclude a diagnosis of a PNH-like abnormality in this patient. If the PNH abnormality is caused by a somatic mutation of the haemopoietic stem cell' ${ }^{5}$ one can postulate that this occurred in our patient as a result of longstanding leukaemia either owing to the disease itself or as a result of treatment with alkylating agents.

We thank Mr P A Jackson, of the biochemistry department, Huddersfield Royal Infirmary, for carrying out the acetylcholine esterase estimation.

1 Dacie, J V, and Lewis, S M, Series Haematologica, 1972, V(3), 3.

2 Sirchia, G and Lewis, S M, Clinics in Haematology, 1975, $4,199$.

${ }^{3}$ Dacie, J V, and Lewis, S M, Practical Haematology, 5th edn. Edinburgh, Churchill Livingstone, 1975.

${ }^{4}$ Hill, R S, Catovsky, D, and Lewis, S M, British Medical fournal, 1972, 4, 649.

${ }^{5}$ Dacie, J V, Proceedings of the Royal Society of Medicine, 1963, 56, 587.

Royal Infirmary, Huddersfield HD3 3EA

D K WATSON, MB, BS, registrar in haematology

A M BARLOW, MD, FRCP ED, consultant haematologist

EILEEN M HEWER, AIMLS, blood transfusion technician 